\title{
Factors determining state of being overweight among the students of Government Medical Colleges of Punjab, Pakistan.
}

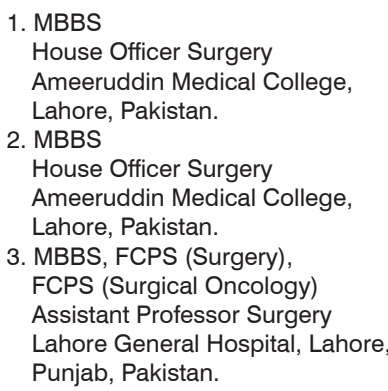

Correspondence Address:

Dr. Arfa Aslam

Department of Surgery

Ameeruddin Medical College, Lahore,

Pakistan.

arfah6692@gmail.com

Article received on: 30/01/2021

Accepted for publication $30 / 03 / 2021$

\begin{abstract}
Arfa Aslam', Usama Ahmed ${ }^{2}$, Awais Amjad Malik ${ }^{3}$
ABSTRACT... Objectives: To determine the prevalence and factors that make medical students of public sector colleges of Punjab, Overweight. Study Design: Cross-sectional study. Settings: 12 different medical colleges of the government sector in Punjab, Pakistan by both online and physical survey using non-probability convenient type of sampling. Period: January 2020 to February 2020. Material \& Methods: A total of 352 students from all five years of the academic course participated in this study. A pre-tested structured questionnaire was self-administered to the students after taking their consent. The data included demographic information, targeted questions on diet, personal health habits, illnesses, and family history. The data was analyzed by the statistical program SPSS version 21. Results: Out of the total population, $28.1 \%$ were male and $71.9 \%$ were female students. The median age was 21.0 years. The mean weight was 59.2 $\pm 11.54 \mathrm{kgs} .56 .3 \%$ of the students were hostelites and $43.8 \%$ were day-scholars. The average pocket-money of the students was 10,150 PKR Per month. According to the body-mass index, about $11.9 \%$ of students were underweight, $12.8 \%$ were overweight, $2.3 \%$ were obese, and $62.5 \%$ were of normal weight. It was found that females were more likely to be overweight than males. Not following any specific diet appeared to be the cause of being overweight while following specific diets was a protective factor against overweight status. Year of study, accommodation status, meals per day, calorie intake, ceremonial eating, hours of sleep, and study had no effect on overweight. Overweight students did not have a significant family history of diabetes mellitus. Conclusions: Poor dietary habits and unhealthy lifestyles increase the prevalence of overweight status among medical students and puts them at increased risk of serious illness in the future. Nutritional counseling and healthy lifestyle awareness are recommended for better practice of health and learning among medical students.
\end{abstract}

Key words: $\quad$ BMI, Diet, Exercise, Medical Students, Nutrition, Overweight, Obesity.

Article Citation: Aslam A, Ahmed U, Malik AA. Factors determining state of being overweight among the students of Government Medical Colleges of Punjab, Pakistan. Professional Med J 2021; 28(12):1850-1856.

https://doi.org/10.29309/TPMJ/2021.28.12.6388

\section{INTRODUCTION}

The graduation period in the life of students is committed to growth in terms of responsibilities, knowledge, and lifestyle practices. During which they are exposed to various challenges of academics and young adulthood. Some of it demands major transitions that hold a significant effect on all domains of health. Medical students face fiercer demands of being competitive in studies and clinical practice, the stress of exams, living in hostels, and more in this period. All of which make them adopt unhealthy lifestyle habits like stress eating, eating fast foods and those which gives satiety more than nutrition, preferring rest over exertion in terms of exercise and substances to avoid sleep and improve concentration.

The relation between nutrition and health was well illustrated by Hippocrates as" If we could give the right amount of nourishment and exercise, not too little and not too much, we could have found the safest way to health". Good nutrition is associated with better physical and mental health, and academic performance..$^{1,2}$

According to NHS, BMI is a basic indicator of nutrition. A BMI between 18.5 to 24.9 is considered Normal, below 18.5 is considered underweight, between 25 to 29.9 is considered overweight and 
above 30 is obese. ${ }^{3} \mathrm{BMl}$ ranges are based on the effect, exercise and body fat has on disease and death. BMI is an indicator of disease as being overweight and obese is related to an increased risk of premature death, cardiovascular diseases, raised blood pressure, cancer, and diabetes mellitus. ${ }^{4}$

Unfortunately, there is no evidence regarding malnourishment among medical students in a developing and third world country like Pakistan on a whole regional level. Although various studies have been done on the prevalence of obesity among medical students and its relation with dietary habits on a population of the specific institution.5,6 For our study, we only focused on students of MBBS. We decided to do the cross-sectional survey among medical students studying in government sector colleges all over province Punjab, Pakistan.

\section{MATERIAL \& METHODS}

This is a cross sectional study involving students studying in medical colleges of government sector all over the province Punjab of Pakistan. The data was collected from January 2020 to February 2020. The students from all five years of MBBS were included in this study. The calculation of this study's sample size used a population of 17,025 which is the estimated total number of medical students studying in all five years of MBBS, in 17 different government medical colleges all over the province Punjab, Pakistan. The confidence interval of the study is $95 \%$ and margin of error is \pm 5 . The estimated sample size was $n=376$ which was calculated by the formula. $\left(S S=Z^{2}{ }^{*} P\right.$ * $1-P /$ $\mathrm{C}^{2}$ )

A special questionnaire was designed, pretested, and then circulated among medical students. Participation in this survey was voluntary and all participants filled consent form for anonymous use of data. The questionnaire consisted of five sections. The first section consisted of demographic information i.e., Gender, Age, Height, Weight, Domicile, Medical Institute, Year of study, Accommodation status, pocket money, and family income per month. The second section was based on questions targeted on diet. To get the information, students were given a chart to fill in meals per day, type of meals and number of servings of food and fluids in every meal and otherwise, snacking and number of fruits per day, ceremonial eating, special diets, and nutritional support. The third section concerned general health habits including daily activities and time spent in these activities, exercise, sleep and study habits and duration of these activities. The daily caloric intake and caloric burnt values were calculated with reference to the values from Park's Textbook of Preventive and Social Medicine. The values were added to the analytical software manually. The fourth section consisted of questions about personal illnesses. The fifth and last section asked about family history.

The questionnaire was distributed both personally by hand and through electronic media among students. A total of 352 students responded to our questionnaire from 12 different medical colleges. All forms were received and data was entered manually into IBM Statistical Package for Social Sciences (SPSS) version 21.0. The frequency of demographic variables was assessed. To identify factors, participants were divided into two categories: Overweight and not overweight. Those with BMl above 25 were all categorized overweight and the rest with BMI below 25 were categorized not overweight. Pearson's Chi-square test was used to check the significance of the relationship between variables and overweight. A p-value of $<0.05$ was taken as significant. This study was approved by ethical review committee of Ameer-ud-din medical college / Lahore general hospital Lahore.

\section{RESULTS}

The response rate was $89.4 \%$ as out of 352 responses 315 students marked correctly in the column of height and weight. Out of these $89.4 \%$ respondents, $28.1 \%$ of students were males and $71.9 \%$ of students were females. Most students who responded were from the 3rd year, followed by the 4th year, 1st year, 2nd year, and 5th year. $56.3 \%$ of the respondents lived in hostels while $43.7 \%$ were day-scholars. Table-l shows all the demographic information of the respondents. 
BMI of the students was calculated and categorized according to ranges given by $\mathrm{NHS}^{3}$. Out of 315 students who responded $62.5 \%$ students had normal weight, $11.9 \%$ students were underweight, $12.8 \%$ students were overweight and $2.3 \%$ students were obese. As shown in Table-II.

We assessed all the students on the basis of their dietary, lifestyle habits, and other reasons for overweight. We found females to be more prone to get overweight ( $p$-value 0.02 ). Year of study did not have any significant effect on overweight. $64.1 \%$ of the overweight students were hostelites indicating that students living in hostels are more prone to being overweight than day-scholars but the results were not significant. More than 90\% of overweight students take 2 to 3 meals per day but there is no significant correlation between meals per day and overweight status. Overweight students appeared to snack more than 2 times between meals in a day but the results were not significant. $14 \%$ of the overweight students take calories more than recommended daily intake but the result was not significant even to that. ${ }^{7,8}$ No correlation was found between overweight and ceremonial eating. Almost an equal number of overweight students eat out more than once a week or less.

We found students who do not follow any specific diet were more overweight than those who follow (p-value 0.00). While following a specific diet was a protective factor against being overweight (weight reduction diet specifically) (p-value 0.002). Relation with low cholesterol, low TAG, or diabetic diet was not significant. Overweight students were found to exercise less but the results were not significant. No correlation was found between overweight, and mode of commute, hours of sleep, and hours of study. As shown in Table-III.

No significant relation was there between overweight and prevalence of headache, breathlessness, fatigue, or insomnia. Change of eating habits with mood also had no significant effect on being overweight. As shown in Table-IV.

Among the positive family history of chronic illnesses prevalence of Hypertension were 47\%, Diabetes 42\%, High cholesterol 20\%, Obesity $17.6 \%$, Myocardial infarction $9.4 \%$, and cancer 2.6\%. No significant correlation was present between the prevalence of overweight and family history of chronic illnesses among medical students. Although $54.7 \%$ of the overweight participants had a family history of diabetes, we did not find a significant relationship for it ( $p$-value 0.056). Similarly, no significant relation was found between being overweight and a family history of hypertension, high cholesterol, obesity, myocardial infarction, or cancer.

\begin{tabular}{|c|c|c|c|c|c|}
\hline \multicolumn{6}{|c|}{ Demographic info: } \\
\hline 1.Participants & \multicolumn{2}{|c|}{$\begin{array}{c}\text { Male } \\
99(28.1 \%)\end{array}$} & $\begin{array}{c}\text { Female } \\
253(71.9 \%)\end{array}$ & \multicolumn{2}{|c|}{$\begin{array}{l}\text { Total } \\
352\end{array}$} \\
\hline 2.Year of study & $\begin{array}{c}1^{\text {st }} \text { Year } \\
69(19.6 \%)\end{array}$ & $\begin{array}{c}2^{\text {st }} \text { Year } \\
60(17 \%)\end{array}$ & $\begin{array}{c}3^{\text {rd }} \text { year } \\
99(28.1 \%)\end{array}$ & $\begin{array}{c}4^{\text {th }} \text { year } \\
85(24.1 \%)\end{array}$ & $\begin{array}{c}5^{\text {th }} \text { Year } \\
39(11.1 \%)\end{array}$ \\
\hline 3.Accomodation status & \multicolumn{3}{|c|}{$\begin{array}{l}\text { Day-scholar } \\
154(43.7 \%)\end{array}$} & \multicolumn{2}{|c|}{$\begin{array}{c}\text { Hostelite } \\
198(56.3 \%)\end{array}$} \\
\hline 6.Family Income & \multicolumn{5}{|c|}{$147927 \mathrm{PKR} /$ month } \\
\hline
\end{tabular}

Table-I. Demographic information.

BMI Range

Underweight $(<18.5)$

Normal Weight (18.5-24.9)

Overweight (25-29.9)

Obese (30 or greater)

Total

\section{Frequency}

42

220

45

8

315
Percent (\%)

11.9

62.5

12.8

2.3

89.5

Table-II. BMI of the participants. 


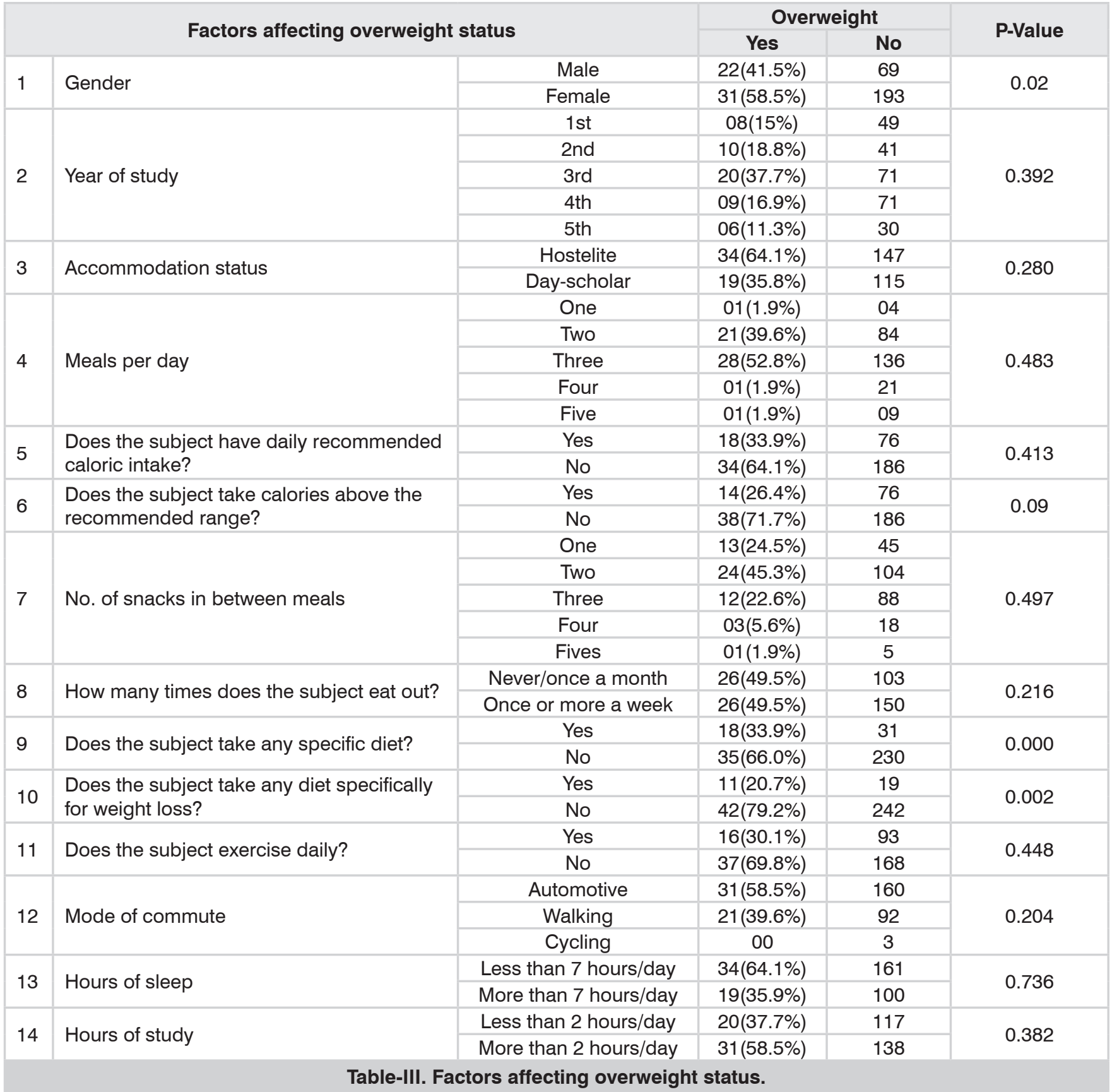

\begin{tabular}{|l|c|c|c|c|}
\hline \multicolumn{2}{|c|}{ Prevalence of Symptoms } & \multicolumn{2}{c|}{ Overweight } & \multirow{2}{*}{ P-Value } \\
\hline \multirow{2}{*}{ Headache } & Yes & Yes & No & \multirow{2}{*}{0.61} \\
\hline \multirow{2}{*}{ Breathlessness } & No & 45 & 46 & \multirow{2}{*}{0.751} \\
\hline \multirow{2}{*}{ Fatigue } & Yes & 8 & 154 & \multirow{2}{*}{0.575} \\
\hline \multirow{2}{*}{ Insomnia } & No & 33 & 103 & \multirow{2}{*}{0.072} \\
\cline { 2 - 4 } & Yes & 20 & 233 & 26 \\
\hline
\end{tabular}




\section{DISCUSSION}

The purpose of our study was to evaluate nutritional status and factors that determine the state of being overweight among medical students. Various researches have been done in past regarding the prevalence of overweight or obesity among medical students around the globe. In our study, according to BMI categories, $13.3 \%$ of the students were underweight, $69.8 \%$ were normal in weight, $14.3 \%$ of students were overweight and $2.5 \%$ of students were obese which is a lot more than Germany where the prevalence of overweight and obesity was $10 \%$ (combined) $^{9}$, but less in comparison to Sudan, Malaysia, and India where the overweight and obese percentage was $22.2 \%$ and $6.5 \%, 30.1 \%$ (combined), $23.6 \%$ and $5.2 \%$ respectively..$^{10-12}$

A literature search shows very few articles about the factors that determine or affect the state of being overweight among students and specifically medical students. No such studies have been done on medical students of the public sector of Pakistan. We tried to find factors that affect overweight status among which gender had a significant effect on being overweight and females were found to be more overweight than males in comparison to the studies in Thailand, Greece, and Botswana that showed overweight and obesity more prevalent among males. ${ }^{15-13}$

Ekpanyaskul C. showed in his study that higher academic years are associated with being overweight in Thai medical students whereas in our study year of study had no correlation with overweight moreover 3rd-year students were more overweight than students in other years. ${ }^{16}$ Abolfotouh at Alexandria University shows a higher prevalence of unhealthy lifestyle and overweight among students living in hostels. ${ }^{17}$ While M. Irfan showed there is no relation between overweight and living in hostels. ${ }^{18}$ In our study, we found a higher prevalence of overweight among hostelites than in Day-scholar but the relation was not significant.

Taking frequent meals and snacks is associated with a gain in weight which affects BMI and thus leads to overweight. Antonio Paoli et al. showed a positive relationship between the number of meals and snacks with raised BMI i.e. those who took more than three meals and snacks in a day had raised $\mathrm{BMI}$ while taking one or two meals a day was associated with lower BMI. ${ }^{19}$ In our study, we found no relation between overweight and the number of meals in a day or the number of snacks taken between meals per day. Similarly, ceremonial eating also had no relation with overweight but there is sufficient evidence in the literature that eating out or eating food made out of home significantly contributes to raised $\mathrm{BMI}$ and increased prevalence of obesity among young age. 20,21

BMI changes with calorie intake. Excessive weight gain is primarily attributed to a persistent positive energy balance where calories consumed exceeds more than calories expanded. ${ }^{22}$ In our study, only $29 \%$ of the students took calories within the recommended range while $37 \%$ of the students took calories more than the recommended daily intake but the relation between increased calorie intake and overweight was not significant contrarily. ${ }^{22,23}$ BA Swinburn in his study showed that taking specific diets is a protective factor against obesity. ${ }^{23}$ Our study also showed a nonspecific diet to be the causative factor for obesity while following a specific diet was protective against obesity.

In our population of medical students, only $33 \%$ of the students did regular exercise which is a lot less when we compared it to medical students in India where the prevalence of daily exercise was $62 \% .{ }^{24}$ Doing exercise regularly is also a protective factor against obesity but we did not find any significant relationship between regular exercise and overweight in our study. ${ }^{14,23}$ Less sleeping time allows for more opportunity to eat, increased appetite, increased food intake, and thus sleep loss could lead to overweight and obesity. K. L. Knuston showed in his study that sleep deprivation is rising in obesity. None of the students sleeps above 8 hours and there is a negative association between sleep deprivation and obesity. ${ }^{25}$ We found that $64 \%$ of the overweight students sleep less than 7 hours but there was no significant relation between hours of sleep and 
overweight. Overweight students perform less in academics as compared to healthy students. ${ }^{26}$ We found no correlation between overweight and duration of study among medical students.

Overweight and obesity are associated with major health consequences i.e., chronic heart diseases, stroke, Type 2 diabetes mellitus, and increased risk of certain cancers. Positive family history of these illnesses and overweight pose the individual at greater risk of morbidity. We found a higher prevalence of a positive family history of chronic illnesses among students but there was no significant relation with overweight. ${ }^{27-29}$

As this is a cross-sectional study, it can only show prevalence of overweight and obesity but not the incidence which puts itat a disadvantage. Whilstwe were able to determine significant relationships, we were not able to determine whether they were positive or negative consistently. This study would also benefit from a large sample size as it would provide more data to work with as well as make it more accurate.

\section{CONCLUSION}

Our study pointed out the prevalence and various factors that determine the state of being overweight and obese among the medical students of public sector colleges all over Punjab, Pakistan. An alarming level of overweight students is present. We recommend that there should be more awareness programs and seminars about healthy lifestyles and proper nutrition. Dietary and exercise counseling should be practiced as a preventive strategy and better facilities should be made possible in hostels to encourage physical activity.

Copyright@ 30 Mar, 2021.

\section{REFERENCES}

1. Zaini MZ, Lim CT, Low WY, Harun F: Effects of nutritional status on academic performance of Malaysian primary school children. Asia Pac J Public Health. 2005:81-7.

2. Godoy AC, Valdés PB, Fariña $\mathrm{CH}$, et al. Association between fitness, nutritional status and academic performance in physical education students. Nutricion hospitalaria. 2015 Oct, 32:1722-8. 10.3305/ nh.2015.32.4.9592.
3. http://Https://www.nhs.uk/common-health-questions/ lifestyle/what-is-the-body-mass-index-bmi.

4. https://www.nhlbi.nih.gov/health/educational/lose_wt/ risk.htm.

5. Nisar N, Qadri MH, Fatima K, Perveen S: Dietary habits and life style among the students of a private medical university Karachi. J Pak Med Assoc. 2009 Feb, 59:98101.

6. Vibhute NA, Baad R, Belgaumi U, Kadashetti V, Bommanavar S, Kamate W: Dietary habits amongst medical students: An institution-based study. J Family Med Prim Care. 2018 Nov-Dec, 7:14641466. 10.4103/jfmpc.jfmpc_154_18. PMID: 30613543 PMCID: PMC6293954.

7. Dietary reference intakes for Energy, Carbohydrate, Fiber, Fat, Fatty Acids, Cholesterol, Protein, And Amino Acids. Washington, DC: National Academies Press;

8. Park: K., n.d. Park's Textbook of Preventive and Social Medicine.

9. Pantenburg B, Sikorski C, Luppa M, Schomerus G, König HH, Werner P, Riedel-Heller SG: Medical students' attitudes towards overweight and obesity. PLoS One. 2012:48113. 10.1371/journal.pone.0048113. Epub 2012 Nov 5. PMID: 23144850 PMCID: PMC3489830

10. Yousif MM, Kaddam LA, Humeda HS: Correlation between physical activity, eating behavior and obesity among Sudanese medical students Sudan. BMC Nutr. 2019 Feb, 6:6. 10.1186/s40795-019-0271-1. PMID: 32153920 PMCID: PMC7050882.

11. Boo NY, Chia GJ, Wong LC, Chew RM, Chong W, Loo RC: The prevalence of obesity among clinical students in a Malaysian medical school. Singapore Med J. 2010 Feb, 51:126-32.

12. Parajuli K, Lamichhane $\mathrm{R}$, Lama $\mathrm{N}$, Marasine NR, Narasannavar A, Shivaswamy MS: Prevalence of overweight and obesity in medical and allied science students of Karnataka, India. Int J Community Med Public Health. 2019, 6:3739-42.

13. Khan ZN, Assir MZ, Shafiq M, Chaudhary AE, Jabeen A: High prevalence of preobesity and obesity among medical students of Lahore and its relation with dietary habits and physical activity. Indian J Endocrinol Metab. 2016 Mar-Apr, 20:206-10. 10.4103/22308210.176357.

14. Chourdakis M, Tzellos T, Papazisis G, Toulis K, Kouvelas $D$ : Eating habits, health attitudes and obesity indices among medical students in northern Greece. Appetite. 2010 Dec, 55:722-5. 10.1016/j.appet.2010.08.013. Epub 2010 Aug 27. PMID: 20801179. 
15. Letamo G: The prevalence of, and factors associated with, overweight and obesity in Botswana. J Biosoc Sci. 2011 Jan, 43:75-84. 10.1017/S0021932010000519. Epub 2010 Sep 17. PMID: 20846466.

16. Ekpanyaskul C, Sithisarankul P, Wattanasirichaigoon $S$ : Overweight/Obesity and related factors among thai medical students. Asia Pac J Public Health. 2013 Mar, 25:170-80. 10.1177/1010539511428665. Epub 2011 Dec 23. PMID: 22199148.

17. Abolfotouh MA, Bassiouni FA, Mounir GM, Fayyad RC. Health-related lifestyles and risk behaviours among students living in Alexandria University Hostels. EMHJ-Eastern Mediterranean Health Journal, 13 (2), 376-391, 2007. 2007.

18. Irfan $M$, Ismail $H$, Zafar $M$ : Nutritional habits and obesity; A case study among Pakistani Universities Students. IJAHS, Apr-Jun. 2018, 02-58.

19. Paoli A, Tinsley G, Bianco A, Moro T: The Influence of Meal Frequency and Timing on Health in Humans: The Role of Fasting. Nutrients. 2019 Mar, 28:719. 10.3390/ nu11040719. PMID: 30925707 PMCID: PMC6520689

20. Binkley JK, Eales J, Jekanowski M: The relation between dietary change and rising US obesity. Int $J$ Obes Relat Metab Disord. 2000 Aug, 24:1032-9.

21. McCrory MA, Fuss PJ, Hays NP, Vinken AG, Greenberg AS, Roberts SB: Overeating in America: Association between restaurant food consumption and body fatness in healthy adult men and women. ages 19 to 80. Obes Res. 1999 Nov, 7:564-71.
22. Buscemi J, Rybak TM, Berlin KS, Murphy JG, Raynor $\mathrm{HA}$ : Impact of food craving and calorie intake on body mass index (BMI) changes during an 18-month behavioral weight loss trial. J Behav Med. 2017 Aug, 40:565-573. 10.1007/s10865-017-9824-4. Epub 2017 Jan 12. PMID: 28083824 PMCID: PMC5501996.

23. Swinburn BA, Caterson I, Seidell JC, James WP: Diet, nutrition and the prevention of excess weight gain and obesity. Public Health Nutr. 2004 Feb, 7:123-46.

24. Rao CR, Darshan B, Das N, Rajan V, Bhogun M, Gupta A: Practice of physical activity among future doctors: A cross sectional analysis. Int J Prev Med. 2012 May, 3:365-9.

25. Knutson KL, Van Cauter E: Associations between sleep loss and increased risk of obesity and diabetes. Ann N Y Acad Sci. 2008:287-304. 10.1196/annals.1417.033. PMID: 18591489 PMCID: PMC4394987.

26. Alswat KA, Al-Shehri AD, Aljuaid TA, Alzaidi BA, Alasmari HD: The association between body mass index and academic performance. Saudi Med J. 2017 Feb, 38:186-191. 10.15537/smj.2017.2.16320. PMID: 28133692 PMCID: PMC5329631.

27. Influence onset and severity of childhood obesity?. Front Endocrinol (Lausanne. 2018 May 2, 9:187. 10.3389/ fendo.2018.00187. PMID: 29770124 PMCID: PMC5941161.

28. Bray GA: Medical consequences of obesity. J Clin Endocrinol Metab. 2004 Jun, 89:2583-9. 10.1210/ jc.2004-0535. PMID: 15181027.

29. Rimárová K, Dorko E, Diabelková J, Sulinová Z, Urdzík P, Pelechová N, Konrádyová N: Prevalence of lifestyle and cardiovascular risk factors in a group of medical students. Cent Eur J Public Health. 2018, 26:12.

\begin{tabular}{|c||l|l|l|}
\hline \multicolumn{3}{|c|}{ AUTHORSHIP AND CONTRIBUTION DECLARATION } \\
\hline No. & \multicolumn{1}{|c|}{ Author(s) Full Name } & \multicolumn{1}{|c|}{ Contribution to the paper } & Author(s) Signature \\
\hline 1 & Arfa Aslam & $\begin{array}{l}\text { Writing, Data Analysis and } \\
\text { writing. } \\
\text { Editing and data collection. }\end{array}$ \\
\hline 2 & Usama Ahmed & Supervising and Editing. & \\
\hline 3 & Awais Amjad Malik & Sots \\
\hline
\end{tabular}

